\title{
El Montepio General de Economía de los Servidores del Estado y el Imperio Brasileño $(1835 / 1883)$
}

Luiz Fernando Saraiva

Rita de Cássia da Silva Almico

Universidade Federal Fluminense

Resumen

El artículo aborda la evolución del Montepío General de Economía de los Servidores del Estado desde su creación, en 1835, hasta su primera gran crisis, en 1883, cuando el Estado intervino para mantener su funcionamiento. En esta trayectoria, vamos a discutir algunas características de los modelos de asociativismo de la sociedad brasileña y el papel ejercido por el Estado en ese proceso, tanto en relación al montepío que es objeto principal de ese artículo, cuanto a otras instituciones de la misma naturaleza asociativa.

Palabras clave:

Montepio; Imperio Brasileño; Liberalismo

Códigos JEL: N30, N36, N86, N96
THE GENERAL ECONOMIC MONTEPIO OF THE STATE SERVERS ANDTHE BRAZILIAN EMPIRE (1835/1883)

\section{Abstract}

The article approaches the subject of the evolution of the General Economic Montepio of the State Servers since its creation, in 1835 , until its first great crisis, in 1883 , when the State intervened to maintain its operation. In this trajectory, we intend to discuss some characteristics of the associativism models in the Brazilian society and the role played by the State in this process, both in relation to the montepio, that is the main object of this article, as well as the others institutions of the same associative nature.

Keywords

Montepio; Brazilian Empire; Liberalism

JEL codes: N30, N36, N86, N96

Fecha de recepción del original: 27 de febrero de 2019; versión definitiva: 6 de mayo de 2019.

Luiz Fernando Saraiva, Profesor Pleno da Universidade Federal Fluminense, Departamento de História, Niterói, Rio de Janeiro, Brasil, Tel.: +55 021 983744775; E-mail: saraivalf@uol.com.br. ORCID ID: 0000-0002-2795-538X

Rita de Cássia da Silva Almico, Profesora Plena da Universidade Federal Fluminense, Faculdade de Economia, Niterói, Rio de Janeiro, Brasil,

Tel.: +55 021 982583245; E-mail: ritaalmico@uol.com.br.

ORCID ID: 0000-0002-0876-9637 


\title{
El Montepio General de Economía de los Servidores del Estado y el Imperio Brasileño
} $(1835 / 1883)$

\author{
Luiz Fernando Saraiva \\ Rita de Cássia da Silva Almico \\ Universidade Federal Fluminense
}

1. Introducción

En este trabajo tenemos se analiza la trayectoria de una de las instituciones de previsión más antiguas de Brasil: el Montepio General de Economía de los Servidores del Estado, creado en 1835 y en funcionamiento hasta hoy, bajo el nombre de Mongeral. El surgimiento y desarrollo de esta institución se dio a lo largo del siglo XIX, cuando el contexto era de implementación de ideas y asociaciones mutualistas liberales en una sociedad fuertemente basada en el trabajo esclavo y en la agroexportación. Estas ideas instituciones serán tratadas en las dos siguientes secciones, (2) así como la introducción de los diferentes modelos de asociaciones de previsión y bienestar a principios del siglo XIX, en comparación con los modelos anteriores basados en la caridad y el cristianismo (economía de la piedad) y (3) la implementación de estas en otros países como, por ejemplo, Portugal y España.

En la cuarta (4) parte de este artículo hacemos un análisis de los datos financieros del Montepío General de Economía de los Servidores del Estado y las estrategias utilizadas por esta institución para sobrevivir a las crisis económicas que tuvieron lugar a lo largo del siglo XIX. El artículo se cierra con algunos apuntes sobre el establecimiento de instituciones de asistencia mutua y previsión en un país como Brasil y los límites impuestos por una sociedad basada en el trabajo esclavo y en la construcción de un Estado que controlaba dicha sociedad.

2. Las ideas económicas en Brasil, Portugal y España

Según Sérgio Buarque de Hollanda, en su obra clásica Raizes do Brasil, la colonización ibérica en América Latina y, en particular, la experiencia lusa en Brasil, dejó como una categoría marcada la ausencia de cohesión interna y lazos de solidaridad en esas sociedades. Según él, "En la laxitud de la estructura social, se debe a la falta de jerarquía organizada algunos de los episodios más singulares de la historia de las naciones hispanas, si incluirlos Portugal y Brasil" (Hollanda, 2004: 33, traducción nuestra)

El establecimiento de la esclavitud como principal forma de trabajo habría reforzado aún más esta característica de la sociedad brasileña y, en las palabras de otro analista clásico de nuestra historia, los hombres libres pobres vivirían entre "señores y esclavos, con una rala e insignificante cantidad de gente libre oprimida entre los extremos antagónicos" (Freyre, 1983: 9, traducción nuestra).

Esta interpretación apunta que esta ausencia de instituciones asociativas, desde los primeros tiempos de nuestra colonización, estaba relacionada a la ausencia de formas de trabajo colectivo constantes o, aún en las palabras de Sérgio Buarque, "Lo que sobre todo nos faltó para el buen éxito de esta y de tantas otras formas de labor productiva fue, seguramente, una capacidad de libre y duradera asociación entre los elementos emprendedores del país " (Hollanda, 1995: 59, traducción nuestra).

Las pocas experiencias de trabajo colectivo tendrían sus límites definidos como transitorios y excepcionales o

Otras costumbres, como el del 'muxirão'o 'mutirão', en que los roceos se socorren unos a otros en las derribadas de matorral, en los plantíos, en las cosechas, en la construcción de casas, en el hilado del algodón, habrían sido tomados de preferencia al gentil de la tierra y se fundamenta, al parecer, en la expectativa de ayuda recíproca, tanto como proporcionada por las cenas, las danzas, los descensos y los desafíos que acompañan obligatoriamente tales servicios. [...]

Por otro lado, sería ilusorio pretender relacionar la presencia de esas formas de actividad colectiva a alguna tendencia hacia la cooperación disciplinada y constante (Idem: 60, traducción nuestra). 
De hecho, la mayoría de las instituciones que "organizaban" la sociedad colonial (ya sean señores, esclavos o los trabajadores libres desposeídos) eran de carácter religioso, como las hermandad de devoción y las Santas Casas de Misericordia, donde aspectos como pobreza e indigencia eran tratadas a partir de una visión caritativa. (Franco, 2014: 5).

Las grandes transformaciones que se experimentaron en Europa desde finales del siglo XVIII trajeron nuevos elementos a la discusión y construcción de asociaciones de auxilio-mutuo y del combate a la pobreza y la mendicidad. Sin embargo, no fueron abandonadas las antiguas formas de organización, hermandad y casas de la misericordia, que continuaron existiendo y expandiéndose en Brasil. En las palabras de Renato Franco

No cabe duda de que estas instituciones continuaron teniendo una importancia fundamental como principales protagonistas de la asistencia. Todas las hermandades fundadas de forma modesta en el siglo XVIII se convirtieron en misericordias en el siglo XIX, indicando un camino casi natural de los establecimientos que se sedimentaban localmente. En buena medida, el modelo de Misericordia que ganó fuerza en el siglo XIX, esparciendo modelos de estatutos considerablemente más permisivos, también contribuyó sobremanera a establecer una memoria de éxito desde los tiempos coloniales. (Idem, traducción nuestra)

En Brasil, de acuerdo con diversos autores, las corporaciones de oficio o cofradías religiosas no tendrán la misma dimensión que en Europa o incluso en la América Española. Este hecho se dio principalmente por el mantenimiento de la esclavitud, lo que diseminó tales oficios entre los esclavos, "transformando en mayoría de cautivos a dichos oficiales" (Silva, 1998, traducción nuestra). Estos gremios y corporaciones de oficio estarán cerrados, en virtud de la ley, en la Constitución de 1824.

La significativa presencia de la esclavitud fue reforzada por el proceso de independencia de Brasil que, en los términos de Ilmar Mattos, provocó un retroceso en el valor de la moneda colonial (Mattos, 2016). Es decir, para garantizar el proceso de independencia y construcción del Estado brasileño, fue fundamental la expansión de las actividades agroexportadoras, lo que, a su vez, significó en términos concretos el recrudecimiento de la esclavitud. Tales hechos no impidieron, al mismo tiempo, un proceso de modernización y racionalización de la sociedad, similar al que ocurría en el 'viejo mundo'. Tanto que vamos a encontrar, aún en las primeras décadas del siglo XIX los primeros movimientos de crear en Brasil cajas económicas, montepíos y otras instituciones que pretendían promover el 'bienestar' de los trabajadores en general (Pereira, 2002).

Estas ideas originarias del pensamiento liberal expresaban nuevas concepciones en relación a las antiguas prácticas asociativas existentes en el mundo ibérico, marcadas por el gran predominio de la religión. Al mismo tiempo, esas ideas se alejaban del pensamiento liberal "puro", de matriz anglosajona, por una originalidad ligada a realidades sociales bastante distintas.
Entre los autores luso-brasileños que han introducido estas ideas, conceptos y nuevas instituciones, vemos la publicación, aún en 1804, de la obra de Adam Smith con los comentarios de José da Silva Lisboa (Barón y más tarde vizconde de Cayru) en el libro Principios de Economía Política. José da Silva Lisboa tendrá una vasta producción en relación con las cuestiones económicas, habiendo producido más de dos docenas de libros que abordan el pensamiento económico de Smith, Edmund Burke, Lord Wellington, entre otros. También se centró en las cuestiones del crecimiento industrial en general y de algunas ramas (como los del vino de Oporto) en particular, estudios sobre legislaciones como de seguros, mercantiles y marítimas, además de las varias reformas políticas (o tentativas de) que Brasil pasó entre 1808 hasta 1831.

Un último aspecto extremadamente representativo del pensamiento del Vizconde de Cayru fue un conjunto de ensayos publicados, separadamente en el espacio de 8 años, entre 1824 a 1832 y ya al final de su vida sobre la relación entre la Religión (católica), el Estado y la economía. En varias de estas obras vemos la condena al tráfico de esclavos y la esclavitud en general a partir de aspectos religiosos (ignominia ante Dios), universales, o iluministas (basado en una idea de igualdad universal entre los hombres) y morales (donde el principal argumento contra la propiedad esclava era de la corrupción que el señor sufrió).

Otro autor destacado fue José Acursio das Neves, que publicó en 1814 la obra Variedades sobre objetos relativos às artes, comércio e manufaturas, consideradas segundo os princípios da Economia Política. Como el propio nombre del libro dice, se trató de un análisis de los más diversos aspectos de la economía luso-brasileña a partir de las ideas de economistas dichos liberales (como Smith, Say, Sismondi, entre otros) con sugerencias para el perfeccionamiento y desarrollo del "Reino". El autor analiza las industrias portuguesas, las relaciones económicas y tratados comerciales entre Portugal, sus colonias y otros países, y también a las instituciones de "nuevo tipo" que debe ser creado. Entre estas instituciones destacan lo que el autor denominaba "Bancos de Economía" que él prefería al nombre de "Cajas Económicas". Sobre esta institución dice:

Hay otra especie de bancos de invención reciente, cuya utilidad es no menos notoria, y que a ningún país puede dejar de convenir: los ingleses le llaman Saving bank; y yo les daré el nombre de banco de economía. Ninguno es más propio para introducir el espíritu de economía en la numerosa clase de los labradores, artistas y obreros. (Neves, 1814, Volumen II: 195, traducción nuestra)

En párrafos anteriores hemos destacado dos aspectos fundamentales de las ideas liberales en Portugal y Brasil, como veremos: la primera es la creencia en los nuevos tipos de instituciones, tales como cajas de ahorros, sino también los montepíos de seguridad, asociaciones científicas y filantrópicas. La segunda cuestión es el carácter tutelar de estas instituciones sobre los trabajadores en general y los pobres en particular. Este será un concepto muy importante en el pensamiento y 
también en las prácticas económicas de la mayor parte de países de tradición latina como Portugal, España (Martínez Soto, 2018) y Francia (Lécuyer, 2004 y Vatin, 2006).

La propia trayectoria de José Acursio das Neves ilustra bien estas características del pensamiento liberal europeo en las primeras décadas del siglo XIX y que tendrá desdoblamientos significativos en Brasil. A pesar de sus ideas liberales en el campo de la Economía, el autor, desde el punto de vista político, asumirá posiciones cada vez más conservadoras, habiendo apoyado al príncipe D. Miguel y su política absolutista en la década de $1830^{1}$.

Varios otros autores liberales se traducirán, tanto en Portugal como en Brasil en ese momento. Entre ellas, destaca el Catecismo de Economia Política ou Instrução Familiar, de Jean Baptiste Say, que fue publicado en Portugal en 1822; el Código Mercantil Francês, de 1807, que fue traducido en 1825 por Antônio José da Silva Loureiro; y el Homem Benfazejo ou das vantagens que resultam aos povos a criação de Caixas Econômicas, de Pierre-Edouard Lemontey, en Río de Janeiro en 1832. Además, varios proyectos de bancos, cajas económicas e instituciones como montepíos se publicaron a ambos lados del Atlántico, adaptando instituciones e ideas que se desarrollaban en Europa a las realidades distintas vividas en las variadas civilizaciones ibéricas.

En varias de estas obras vemos la evolución del pensamiento típico del Antiguo Régimen, que asociaba el tratamiento de la pobreza al espíritu de caridad cristiana hacia una concepción más racional que intentaba disciplinar mendigos y marginales a través del trabajo y de los hábitos de economía. En España, parte de estas ideas ya pueden ser percibidas desde el final del siglo XVIII, como en el pensamiento de Francisco de Cabarrús publicado en 1783, Cartas sobre los obstáculos que la naturaleza, la opinión oponen a la felicidad pública, en ese trabajo, y en otros, el autor asociaba la pobreza justamente a la existencia de instituciones que los amparaban, como los hospicios y misericordias. El autor propuso que estas 'antiguas' instituciones fueran 'modernizadas', asociando a sus asistidos a las obras públicas y demás tipos de trabajo para impedir la mendicidad y la pereza (Martínez Soto, 2018).

Sin embargo, la diferencia de España donde el gobierno liberal, a partir de 1820, intentó separar la protección a los trabajadores de las instituciones religiosas, en Brasil, el mantenimiento de la iglesia en el régimen del Patronato y la ausencia de una política 'nacional' de Socorros Públicos permitió que convivieran a lo largo de todo el período con el crecimiento de instituciones religiosas como Orfanatos, Misericordias, Hermandades e instituciones denominadas 'modernas', como las Cajas Económicas y los Montepíos dedicados a las pensiones a los trabajadores jubilados o a su familia (Martínez Soto, 2018, Franco, 2014, Almico y Saraiva, 2008).

\footnotetext{
1 Miguel era hermano del Emperador de Brasil Pedro I, posteriormente Pedro IV de Portugal, en 1831 asumió el trono de Portugal como Príncipe Regente de su sobrina estableciendo un gobierno de fuerte carácter autoritario. Se enfrento a su hermano en una guerra civil (1831-34) y fue derrotado.
}

\section{Orígenes y límites el Asociacionismo en Brasil}

Si los orígenes del pensamiento asociativo en España, Portugal y Brasil provienen de finales del siglo XVIII, las primeras asociaciones con este carácter "renovada" apareció por primera vez en Brasil después de la independencia, con la creación del Montepío del Ejército por la ley de 6 de noviembre de 1827. La creación de esa institución ocupó buena parte de los debates en la $1^{\text {a }}$ legislatura de la Cámara de Diputados en el año 1826. La premura de ese debate estaba relacionada a los muertos durante las guerras de nuestra independencia y el proyecto que dio origen al montepío fue propuesto por el Coronel del Cuerpo de Ingenieros, Francisco José de Souza Soares d'Andrea, sometido el 10 de julio de ese mismo año.

Durante estas discusiones se propuso más de una vez la creación de un Montepío General para todos los servidores del Estado. Funcionarios de otros aparatos del Estado también llevaron sus demandas a la Cámara de Diputados, como los funcionarios empleados de la Junta de Hacienda de la Provincia de Bahía².

Esta primera legislatura del Imperio del Brasil (1826-1830) estuvo marcada, en gran medida, por las leyes que intentaron "deconstruir" las viejas instituciones heredadas de la estructura administrativa portuguesa, y, además, garantizar líneas generales de derechos para el ciudadano. Este esfuerzo tuvo continuidad en la siguiente legislatura (1831-1835), después de la abdicación del emperador D. Pedro I, donde se tomaron una serie de medidas liberales. Sin embargo, la coyuntura de conflictos sociales y políticos vividos por el país en la segunda mitad de la década de 1830 interrumpió tal proceso, asumiendo el Estado (y el legislativo brasileño) posiciones bastante conservadoras (Saraiva y Francia, 2011, Vantuil Pereira, 2010).

De todos modos, la década de 1830 fue marcada, en Brasil, por una gran efervescencia desde el punto de vista de asociaciones mutuas, políticas, científicas y culturales. Motivada en gran parte por la continuidad del proceso de independencia y construcción del Estado Brasileño, estas instituciones fueron favorecidas por la abdicación de D. Pedro I en abril de 1831. El ideario liberal y de libre asociación se extendió y fue una de las principales características del período que asistió al surgimiento de diversas instituciones, como el Montepío del Ejército; la Sociedad de los Amantes de la Instrucción (1829); la Sociedad Auxiliadora de la Industria Nacional, Defensora de la Libertad e Independencia Nacional y la Caja Económica de Río de Janeiro (todas de 1831); la Caja Económica de São Paulo, de la Ciudad de Bahía (en 1834); la Caja Económica de Campos, el Montepío General de Economía de los Servidores del Estado y la Caixa Económica de la Asociación Comercial de Recife (en 1835); la Caja Económica de Ouro Preto, el Monte de Socorro y el Instituto Histórico y Geográfico de Brasil (1838) y el Montepío General (1841).

\footnotetext{
2 Imperio do Brasil : Diario da Camara dos Deputados (RJ) - 1826, Edição 00044 (3) Discurso del Diputado Costa Aguiar e Edição 00058 (2) Diputado Cunha Mattos en el año 1827, Edição 00016 (1)
} 
De estas, las que nos interesan más de cerca son la Caixa Económica de Río de Janeiro, el Montepío General de Economía de los Servidores del Estado y el Montepío General y que van a tener trayectorias distintas a lo largo del siglo XIX. El Estado brasileño tuvo actuaciones diferentes en relación a esas instituciones, prácticamente forzando el cierre de la Caja Económica en 1859, decretando el fin del Montepío General en 1883 y apoyando a lo largo de todo el período el Montepio General de Economía de los Servidores del Estado, rescatándolo varias veces, incluso en el momento de la crisis que llevará al cierre del Montepio General.

Tales trayectorias son visibles en las tres asociaciones señaladas. Aunque con 'públicos' y objetivos distintos, esas instituciones tenían en común algunos aspectos: primero estarían compuestas por libre-asociación de los ciudadanos; segundo invirtieron los capitales depositados en títulos de deuda pública; y, tercero tendrían gestiones controladas por asociados nombrados en régimen de asamblea. La fuente de inspiración de esas asociaciones fue el pensamiento liberal francés del contexto post-napoleónico en que se intentaba conciliar la protección social de los trabajadores a una alianza con el Estado restaurado del Congreso de Viena (Saraiva, 2014).

La Caja Económica de Río de Janeiro fue la primera de estas instituciones, habiendo sido creada al margen del Estado Imperial en junio de 1831. Fundaron la Caja cerca de 60 ciudadanos de los altos extractos de la sociedad de la Corte y el objetivo explícito era inculcar el hábito de la perseverancia en el ahorro entre los trabajadores pobres, los huérfanos e incluso los esclavos. Su trayectoria tuvo una significativa importancia en la década de 1830, donde logró reunir poco más del $14 \%$ del total de títulos de la deuda pública emitidas por el gobierno brasileño en el período y alcanzó un número de asociados de al menos 6.000 personas de los más distintos orígenes sociales, incluyendo un número significativo de esclavos, mujeres, niños y trabajadores pobres. En 1840, año del auge de la actividad de la Caja Económica, ésta poseía cerca de 3.408:737\$300 ( $£ 435.462,84)$ lo que correspondía en ese momento un porcentaje altísimo de la deuda externa del país.

Ya en las dos décadas siguientes, la institución enfrentará dificultades vinculadas a la moratoria que el gobierno imperial impuso al rescate de los títulos de la deuda (lo que rebajó enormemente el valor de los mismos) y una competencia creciente de instituciones particulares, como casas bancarias de grandes comerciantes de la corte y bancos que crearon modalidades de depósito remunerados con intereses superiores a los pagados por la Caja Económica.

Tales dificultades llevaron a sus creadores a intentar modificar sus estatutos para operar con préstamos, puestas y otras inversiones, diversificando, por lo tanto, sus fuentes de ingresos. A esto se unió la actuación del gobierno en la década de 1850, que adoptó una postura francamente conservadora, imponiendo a todas las asociaciones comerciales, financieras y bancarias la necesidad de que sus estatutos fueran aprobados por el Consejo de Estado. A pesar de los varios intentos, la Caixa Económica de Río de Janeiro no logró aprobar esos cambios y la crisis económica de 1857 acabó por socavar el funcionamiento de la misma, lo que llevó a su disolución (Alvarenga y Saraiva, 2018).
La creación del Montepío General de Economía de los Servidores del Estado, a diferencia de la Caja Económica, fue marcada por la actuación directa del Estado Imperial. Se estableció por decreto el 10 de enero de 1835, sus estatutos fueron discutidos durante toda la legislatura de ese año, siendo finalmente aprobados en el año 1836. Su análisis será más detallado en la próxima sección, pero por ahora basta con decir que tuvo su supervivencia ligada a los constantes beneficios que le garantizó el gobierno brasileño por todo el siglo XIX. Limitada a los funcionarios públicos del recién creado Estado Brasileño, será la única de las tres instituciones que ha sobrevivido hasta el actual momento, lo que es bastante expresivo del contexto de asistencia social existente en el siglo XIX. En el año de la proclamación de la República, por ejemplo, el Montepío poseía cerca de 7.218:044\$659 $(£ 678.387,59)$ en pólizas, dinero y letras.

Por último, la creación de un Monte Pío General que apuntaba a la adhesión de todos los trabajadores también fue discutida por la Cámara y el Senado brasileño desde la primera legislatura en 1826. Su aprobación, el 27 de septiembre de 1841, estableció reglas similares para los asociados de la Caja Económica de 1831, aunque excluía esclavos, huérfanos y mujeres como posibles accionistas. Su trayectoria logró recoger expresivos recursos como las otras dos instituciones y, cuando de su quiebra, en 1883, tal montepío poseía cerca de 7.400:000\$000 (alrededor de $£ 658.362,98)$. Su quiebra fue fruto tanto de la poca remuneración propiciada por los títulos de la deuda pública, del exceso pagado a pensiones como denunciado varias veces por la prensa, como por la competencia de instituciones más 'cercanas' de los trabajadores, como los montepíos profesionales establecidos en varias regiones del país.

Entre las décadas de 1860 a 1880, por ejemplo, asistimos a la creación de más de 400 instituciones de carácter asociativo en todo el territorio brasileño, la gran mayoría de éstas eran instituciones de auxilio mutuo y tuvieron vida efímera, como la Sociedad Brasileña de Beneficencia (1861), el Montepio de los Artistas de la Corte (1872), la Sociedad Montepio Artístico Familiar (1876), o la Sociedad de Socorros Mutuos Marqués de Pombal (1882). Estas asociaciones eran, en su gran mayoría, de corte étnico-racial o por categorías de trabajadores y la ausencia de estadísticas o datos oficiales demuestra cómo esos temas ocupaban poco la pauta política del Estado Brasileño.

Al comparar estas tres instituciones brasileñas de las experiencias de Portugal y España, algunas características son evidentes en los límites que el pensamiento y las prácticas liberales han tenido en Brasil. En Portugal, el resultado de sus circunstancias políticas de la década de 1820 (Revolución liberal de Oporto) y 1830 (Guerra Civil), la organización de las primeras instituciones asociativas se produjo sólo una década más tarde, en 1840, pero de una manera más articulada. El 25 de agosto de 1840 fue creado el Monte Pío de los Empleados Públicos que, en sus estatutos, preveían la creación de una Caja Económica y, además, de un Montepío General. Esta institución trabajó con la satisfacción de haber creado la Caja de Ahorros de Lisboa en 1844 (la primera en Portugal) y todavía universalizar el Montepío para todos los trabajadores, no sólo los servidores públicos. (Pistola, 2018)

En España tenemos datos organizados sobre la asistencia social desde 1787, compilados en anuarios estadísticos a partir 
de mediados del siglo XIX (como 1858, 1862 y otros años). En estas encuestas nos damos cuenta de que la evolución de la asistencia social en ese país fue más intensa que en Brasil o incluso en Portugal. De hecho, si en 1787 existían 903 instituciones de asistencia social en España (básicamente Hospitales, Hospicios y Orfanatos), en 1858 ese número había subido a 1.761 establecimientos, incluyendo allí Cajas Económicas, Montepíos de varias naturalezas y otras sociedades de naturaleza distintas (Martínez Soto, 2018: 111 y 114).

Estas posturas diversas muestran las varias coyunturas políticas por las cuales el Imperio de Brasil atravesó, alternando períodos donde el pensamiento y las prácticas liberales eran más destacadas, con otros en que las ideas de carácter más centralizador y conservador predominaban. Además de esas posiciones políticas, un rasgo que se mantuvo constante fue el del control que el gobierno pretendía ejercer sobre la sociedad en general y esas instituciones en particular, fruto de una sociedad esclavista, este control no significó un proyecto nacional de asistencia social o un proceso de lenta gestación de instituciones modernas.

De hecho, gran parte de las instituciones de asistencia social a lo largo del Imperio Brasileño - como Hospitales, Hospicios, Orfanatos y otras - permanecieron en manos de las antiguas asociaciones religiosas y fueron prácticamente el único tipo de asistencia que partes significativas de la población brasileña tuvo en el período.

4. La evolución del Montepio General de los Servidores del Estado

El Montepio General de Economía de los Servidores del Estadofue formado por influencia de Aureliano de Souza Coutinho que también participó en la creación de la Caja Económica de Río de Janeiro, del Monte de Socorro y del Montepío General, respectivamente en 1831, 1838 y 1841 . Este personaje tuvo una trayectoria bastante destacada en el período regencial y al inicio del segundo reinado, habiendo participado en diversos gabinetes y habiendo sido ministro de los negocios del Imperio de Brasil (1833), de la Justicia (1833-35) y de las Relaciones Exteriores (1834-35; 1840-43). Su formación académica se dio en Coimbra, habiendo estudiado Derecho entre los años 1820 y 1825, cuando regresó a Brasil y ejerció diversos cargos como Juiz de Fora y Ouvidor en Minas Gerais, donde entró en la política como Diputado, aún en la primera legislatura. De postura liberal-moderada, poseía una disposición 'generosa' en relación a las capas populares, como muestra su actuación política y aún en la prensa.

La estructura de funcionamiento del Montepío fue similar a la mayoría de las instituciones creadas en el período y si se daría por la recepción de las joyas (que era el derecho de asociarse a los montepíos) y de las anualidades (que correspondería a una veintena o el $5 \%$ del salario recibido). Después de un período variable de contribución, el Montepio pagaría una pensión a los socios remitidos, a sus viudas e hijos hasta cierta edad.

Los estatutos iniciales del Montepio proponían que se celebrara una asamblea cuando éste alcanzara a sus cien primeros socios, similar a todas las instituciones creadas en el período. Cuando de esa asamblea, sería elegida, por voto secreto, la dirección compuesta por el presidente, tesorero, secretario y dos directores. Entre los socios se sortearon, además, 12 directores adjuntos para acompañar a la dirección en las necesidades y reuniones extraordinarias. Esta primera asamblea general ocurrió el 14 de junio de 1835, aún en su primer año de existencia, pero los estatutos finales del montepío tardaron un poco más para ser aprobados, habiendo ocurrido sólo el 22 de julio de 1836.

La primera dirección, además de organizar los estatutos y tomar las primeras providencias para la consolidación de la institución, logró del gobierno imperial autorización para que las reparticiones del ministerio de la Hacienda en las provincias funcionasen como representantes del montepío - tanto en la recogida de las contribuciones, como en el pago de las pensiones -, lo que le daba un importante estatus: el alcance nacional de sus asociados. Además de ese privilegio, el montepío obtuvo del Estado el derecho de tener cuatro loterías anuales para componer el patrimonio de la institución. También sería beneficiado por exenciones de impuestos y tasas, préstamos y donación de inmuebles, préstamos en efectivo y perdón de deudas, lo que demuestra el buen tránsito que poseía con el gobierno del Imperio. Estos privilegios y la buena relación con el gobierno imperial puede ser un importante factor que explique la quiebra de tantas otras instituciones del mismo período y la supervivencia del montepío de servidores hasta los días de hoy.

Este gran poder que el montepío gozará junto al Estado Imperial Brasileño estaba ligado al perfil de sus asociados y también a la elección estratégica de sus presidentes y directores. Al analizar la lista de los presidentes del montepío, en el período entre 1835 y 1900, encontramos 5 Consejeros del Estado, 1 Senador, 1 Desembargador, 1 Marqués, 3 Vizcondes y 1 Barón. La mayoría de sus directores y secretarios se compuso de Consejeros, Desembargadores y Jueces, o sea, las categorías más altas entre los funcionarios públicos y de la propia sociedad imperial. Esta elección de presidentes con importantes trayectorias políticas generó, inclusive, problemas en la administración del Montepío. Ejemplo de esto se registra en 1859, año en que se produjo una reforma en los estatutos que creó el cargo de Vicepresidente "pues siendo a menudo Ministro de Estado el ocupante de la presidencia del montepío, se veía bastante perjudicado con las ausencias constantes de su presidente" (Pereira, 1952: 06, traducción nuestra).

Las fuentes acerca del perfil de los asociados son raras. Pero, aunque no es posible identificar las principales actividades económicas de los miembros del montepío, fuentes cualitativas, como periódicos de la época, nos apuntan a una mayoría de socios siendo funcionarios públicos que ocupaban los cargos más elevados. Esta característica promueve una significativa diferenciación en relación a las asociaciones congéneres existentes en el siglo XIX. Miramos, por ejemplo, en el 
Gráfico 1. Número de miembros del Montepio General de los Servidores del Estado (años seleccionados)

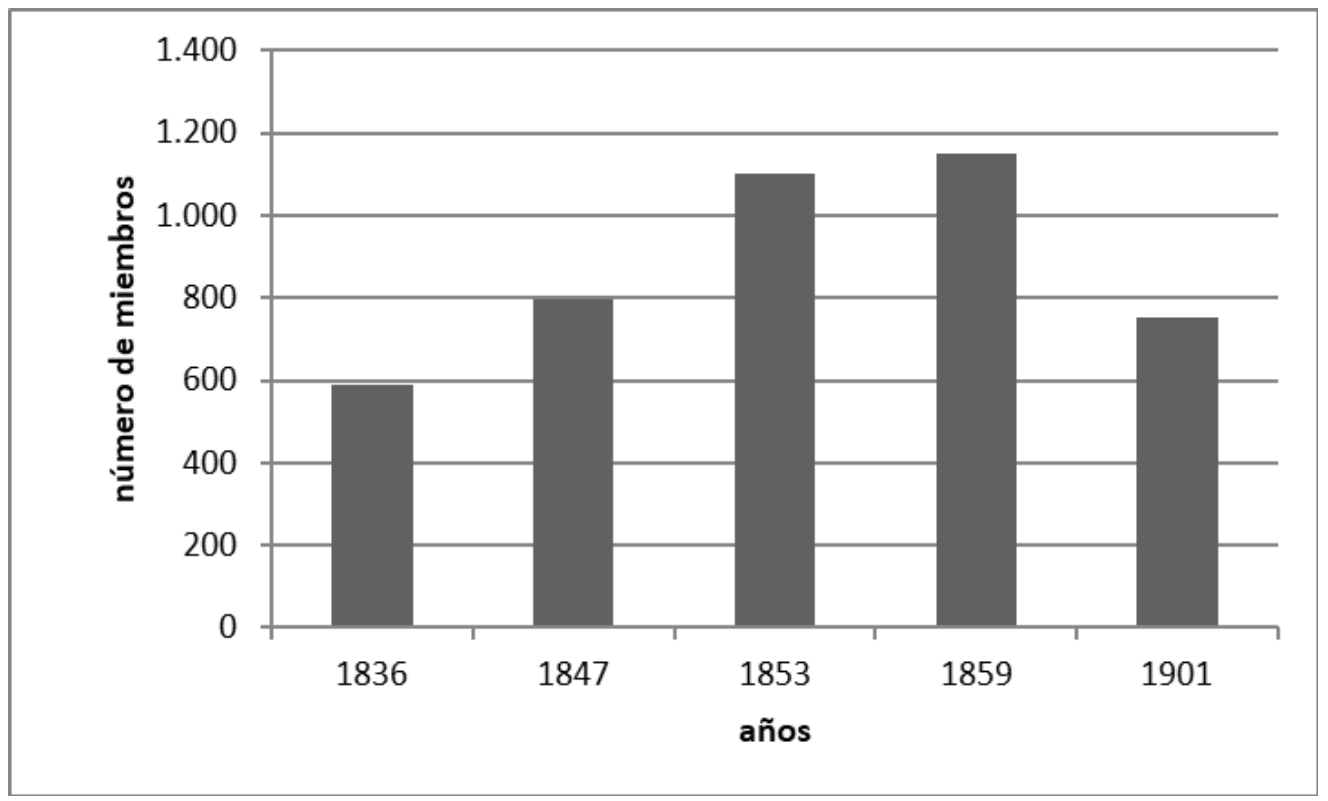

Fuente: Pereira, 1852: 4-10.

informe del Marqués de Paranaguá para el bienio 1887 - 1889 la adhesión de nuevos socios al montepío como el Coronel Antônio José María Pego Junior, los Capitanes Agrícolas Ewerton Pinto y Alexandre Carlos Barreto, el Alferes Antônio José Lino da Costa, además del Barón de Aguiar de Andrada o Francisco Xavier de la Costa Aguiar de Andrada que, además de haber sido Juez de Derecho, fue también embajador brasileño en varias misiones diplomáticas (Pereira, 1952: 7).

La garantía de estar asociado al Montepío y poder gozar de los beneficios ofrecidos implicaba el pago con dinero o joyas de las anualidades y tasas de inscripción, obligación de los funcionarios que desearan esa inserción. Como los salarios eran elevados, una de las características de esas categorías de funcionarios públicos que eran socios del montepío, también mayores eran los valores de los pagos exigidos. De la misma forma, las pensiones eran significativamente mayores que las de las otras asociaciones que existían en Brasil en aquel momento. Si comparamos con las tasas cobradas en otros montepíos del país, como por ejemplo el Montepio Casas de los Artistas de Salvador ${ }^{3}$, observamos valores bien distintos. La institución soteropolitana cobraba con joyas y diplomas (que servían como una especie de inscripción) la cantidad de $22 \$ 000$ (veintidós mil reis) y las mensualidades tenían el valor de $1 \$ 000$ (mil reis) - normalmente estos valores eran fijos. En el Montepio General de Economía de los Servidores del Estado, para el mismo período, los valores son mucho más elevados. La inscripción, las joyas y las anualidades (que podrían dividir-

\footnotetext{
3 Haremos comparaciones con el Montepio Casas dos Artistas de Salvador por estar ubicado en una capital de provincia, con una importacia económica significativa, ser de naturaliza privada y servir de contrapunto tanto para los privilegios como para el público y los valores operados.
}

se y pagarse mensualmente) variaban de acuerdo con la edad y las 'bandas' de pensión pretendida por los candidatos a la sociedad. Veamos el bienio de 1887/1889: las inscripciones costaban entre $200 \$ 000$ y 2:400\$000 (doscientos mil reis y dos cuentos y cuatrocientos mil reis respectivamente); las joyas variaban entre $282 \$ 000$ y 4:608\$000 (doscientos ochenta y dos mil reis y cuatro cuentos y seiscientos y ocho mil reis respectivamente); y las mensualidades, a su vez, podían ser cobradas entre $2 \$ 500$ y $118 \$ 000$ (dos mil quinientos reis y ciento dieciocho mil reis, respectivamente).

El número de miembros del Montepio General de Economía de los Servidores del Estado también es superior cuando comparado a los demás montepíos del país. No tenemos datos exactos para todo el período, sin embargo, la información de varios informes encuadrados nos apunta que los números de socios del Montepio eran, como se demuestra en el Gráfico I, muy superiores a las demás instituciones. Seleccionamos los años de 1836, 1847, 1859 y 1901 para demostrar, desde el momento de su fundación, la elevación del número de asociados. En el primer año el número de socios ya superaba, en mucho, a los 500 miembros, casi alcanzando los 600 asociados. Once años después, cerca de 800 personas componían el cuadro de socios, cantidad de personas que sobrepasaría los mil asociados en 1853 y 1859 y caería a unos 700 asociados a principios del siglo XX.

Este elevado número de socios se debe al hecho de que, desde su fundación, el Montepío General de Economía de los Servidores del Estado asumió una dimensión 'nacional', lo que sólo fue posible con el apoyo del Estado Imperial que permitió el uso de su aparato burocrático para servir de representante del montepío en las demás provincias del Imperio, además de la Corte. Además, el número de funcionarios públicos en 
el Brasil del siglo XIX era, de lejos, una de las más numerosas 'categorías profesionales' del período.

Para organizar y mejor administrar los ingresos del montepío y el pago de las pensiones, los estatutos del Montepio sufrir varias reformas a lo largo del siglo. Estos cambios sirvieron para organizar mejor la institución y, en la mayoría de las veces, pretendían aumentar los ingresos para enfrentar coyunturas de crisis. La reforma de los estatutos ocurrida en 1837, por ejemplo, pasó a prohibir socios con edad superior a 60 años; también, como buen ejemplo, la contribución proporcional de acuerdo con la edad, que será regulada en la reforma de 1844.

En cuanto al patrimonio, es común encontrar en las inversiones de las instituciones de esa naturaleza una variada gama de activos, como por ejemplo, hipotecas, pales, edificios, títulos de deuda pública, entre otros. En lo que se refiere al Montepío de Economía de los Servidores del Estado ese perfil no corresponde fielmente a la realidad. Esta institución poseía, en 1847, por ejemplo, 1.689 pólizas de la deuda pública como componentes de su patrimonio. En 1889, esa cantidad de pólizas de la deuda pública general y provincial sumaba 7.580 títulos. La elección por invertir en títulos de deuda pública es una influencia directa que percibimos de los orígenes de las asociaciones liberales de la década de 1830 por fuerte influencia del pensamiento francés.

Esto se debe al hecho de que ese activo se considera seguro, a pesar de los intereses más bajos que otras inversiones de retorno más arriesgado. De esta forma, por otro lado, el Estado Imperial podía contar con el montepío para préstamos indirectos hechos vía emisión de títulos de deuda pública y comprados por esta institución, entre tantas otras. Los beneficios obtenidos junto al Estado Imperial eran respondidos con la compra de títulos de la deuda pública. Algunas instituciones del período, como la Caja Económica de Río de Janeiro, tenían en sus estatutos la obligatoriedad de compra de títulos como inversión, lo que no era el caso del montepío de los servidores (Saraiva, Alvarenga, 2018).

No tenemos indicación de inversión en inmuebles, por ejemplo, hecho bastante común para otras instituciones de previsión en ese momento ${ }^{4}$. La propia sede del Montepio no fue comprada con el fruto de los ingresos de la institución. En principio, el montepío utilizaba algunos edificios de reparticiones públicas como su sede y, en 1841, fue alquilado un inmueble en la Travessa das Belas Artes, n० 9, en el centro de Río de Janeiro (la sede de la empresa funciona en esa misma dirección hasta hoy) para ser la sede del montepío. Esta sede será, posteriormente, donada al Montepio por el Estado Imperial (1854) en otra demostración de los sucesivos beneficios que el gobierno del Imperio proporcionaba a esa institución.

Al analizar las formas de contribución percibimos que éstas eran variadas. Por tener una naturaleza de agregar trabajadores que servían al Estado y, por ser este Estado presente en las más variadas reparticiones públicas distribuidas por el país $y$, aún, por ser este país de proporciones continentales, visto su extensión territorial, algunos casos, además de curiosos,

\footnotetext{
${ }^{4}$ En el caso del Montepío Casa do Artista Cachoerianos, de la ciudad de Cachoeira donde la mayor parte de las inversiones se dirigían a la adquisición de inmuebles de la propia ciudad (Almico y Saraiva, 2008)
}

demuestran la preocupación en ahorrar a través de la contribución y de los arreglos hechos para no faltar con ese pago.

Un socio residente en Pará, asustado de perder la inscripción por falta de pagos, debido a dificultades de comunicación con esta lejana provincia, envió al Directorio en depósito, una póliza de la Deuda Pública, cuyos intereses anuales representaban justamente la contribución a la que era obligado (Pereira, 1952: 22, traducción nuestra).

En general, las asociaciones de previsión privada pasaron por numerosas dificultades financieras, lo que llevó a la quiebra de muchas de ellas. Las principales dificultades encontradas por estas asociaciones, por regla general, son del orden del incumplimiento de sus socios. Pero, en el caso del Montepio General de Economía de los Servidores del Estado, tales dificultades, aparentemente, se dieron más por la deficiente gestión, el gran número de pensiones pagadas, los fraudes diversos y la pérdida de recursos de la institución. A partir de 1864 se asiste a constantes reclamaciones de la directiva por la crisis que estaría por caer sobre la asociación. Esta coyuntura es de crisis en la plaza de Rio de Janeiro, una vez que fue en este año la "Crise de Souto", el nombre por el cual se conoció la crisis económica vivida por la economía carioca tras la quiebra de la casa comercial A. J. Alves \& Souto \& Co., que llevó a la bancarrota no sólo esta casa comercial, sino otras más directamente vinculadas a ella, además de alcanzar agentes de otras ciudades que mantenían relaciones económicas con Río de Janeiro ${ }^{5}$.

Algunas medidas se tomar para evitar estas dificultades financieras, tales como disminución de los salarios de los empleados, descuento del $10 \%$ de las pensiones pagadas e instalación de varias comisiones médicas para evaluar a los ingresantes con el fin de averiguar el estado de salud de los mismos. Pero también hubo un Ilamamiento al Estado imperial para que los privilegios concedidos al montepío fueran ampliados. Por ejemplo, fueron las reclamaciones hechas al Gobierno para que las loterías pasaran a ser mensuales (12 por año) y no sólo las cuatro anuales, como acordado en el origen del montepío. Esta petición fue atendida de acuerdo con el decreto de 22 de agosto de 1866, cuando el Estado autoriza las loterías mensuales, lo que garantizó el aumento de los ingresos. En 1867/1869 la dirección dobló el descuento de las pensiones pagadas. De $10 \%$ esos descuentos pasarían al porcentaje del 20\%. En la tercera presidencia, la del Consejero José María da Silva Paranhos, el Visconde del Río Branco (1869/1871), se emprendieron otras reformas. Hube a autorización de continuidad de las loterías mensuales, fin del pago de los impuestos cobrados sobre estas mismas loterías, mayor fiscalización de la situación real de salud y edad de los socios, organización de una "tabla de vida media" - en un intento de organizar mejor la salud de las cuentas futuras del montepío - y la disminución de las pensiones para viudas de "nuevas nupcias", es decir, para aquellas que se casaron de nuevo (Pereira, 1952: 57).

\footnotetext{
${ }^{5}$ Cf. ALMICO, 2015 (especialmente el capítulo 1)
} 


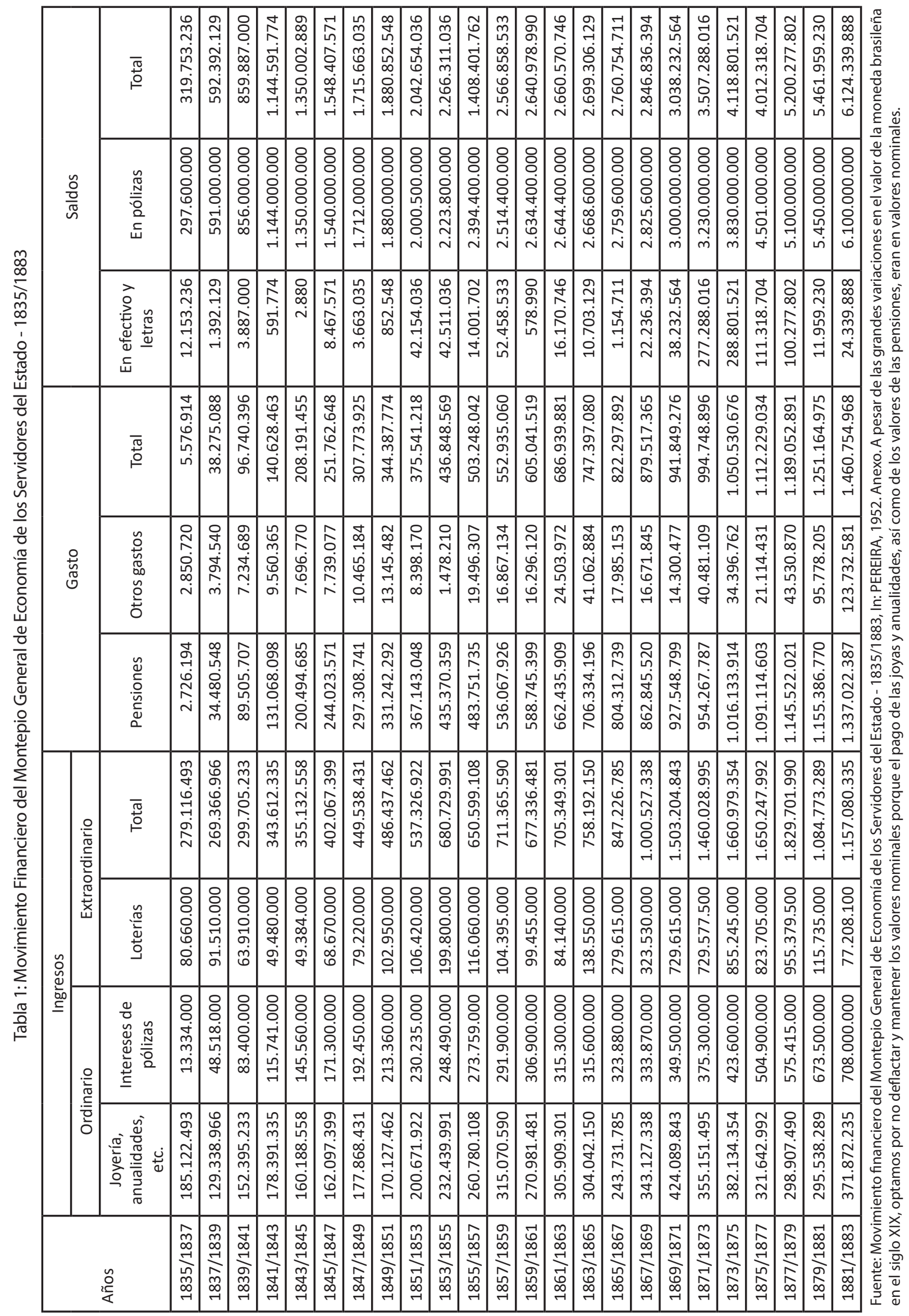


Sin embargo, la crisis no será superada y, en 1885, nuevamente el gobierno imperial acudió al montepío. En el siguiente trecho, vemos algunos de los 'favores' que el gobierno y la Cámara de Diputados dieron al montepio, cuando

\section{Apelando la Dirección del Montepio al Gobierno Imperial logró que la asamblea general legislativa extinguiera el pernicioso sistema de las loterías provinciales ser organiza- das y vendidas en la corte [sic]. Estas loterías hacían grave competencia a las loterías generales, principalmente las concedidas al Montepio (Ídem, traducción nuestra).}

Era común en el siglo XIX que los montepíos del país utilizasen el beneficio de las loterías, concedidas por los gobiernos provinciales, como forma de aumentar/complementar sus ingresos. La Corte (y el entorno de Río de Janeiro) era el principal mercado para esas actividades, no sólo por el volumen de capital en la región, sino también por la expresiva población que allí vivía. Al pedir exclusividad para las loterías generales, el Montepio de Economía de los Servidores del Estado estaba, en realidad, limitando el acceso a nuevas y expresivas rentas para otras instituciones congéneres del país. Las rentas generadas por las loterías eran muy expresivas y el montepio contó con esa renta para costear sus gastos durante todo el período estudiado.

El 3 de septiembre de 1885, la sede del montepío sufrió un atentado a través de un incendio criminal. El secretario de la institución, acusado de desviación de recursos, tuvo una implicación comprobada por la posterior investigación de los hechos. El objetivo del incendio era destruir las pruebas de esos delitos. El Incendio, además de los daños materiales, destruyó parte significativa de la documentación de la institución. Aparentemente esos fraudes eran constantes y no ocurrían sólo en la sede. En 1887/1889 el presidente del Montepio, el Vizconde de Paranaguá, abolirá la práctica de recibos sueltos porque, según éste, la práctica permitía todo tipo de abusos por parte de aquellos que recibían las mensualidades en las diversas provincias. También instituyó el examen obligatorio para todos los ingresantes en el montepio, denotando que procedimientos fraudulentos ocurrían también con el pago de pensiones bastante expresivas a socios que poco o nada contribuyeron con la institución (Pereira, 1952: 63).

Es importante, para comprender mejor la importancia de esta institución, analizar los datos generales de la contabilidad de Montepio. De esta forma, podemos percibir que la crisis por la que la institución pasaba en la segunda mitad del siglo XIX estaba directamente vinculada, además de otros motivos, al número insuficiente de socios (o mejor, de pagos) en relación

Gráfico 2: Movimiento financiero del Montepio General de Economía de los Servidores del Estado - 1835/1891 (en réis)

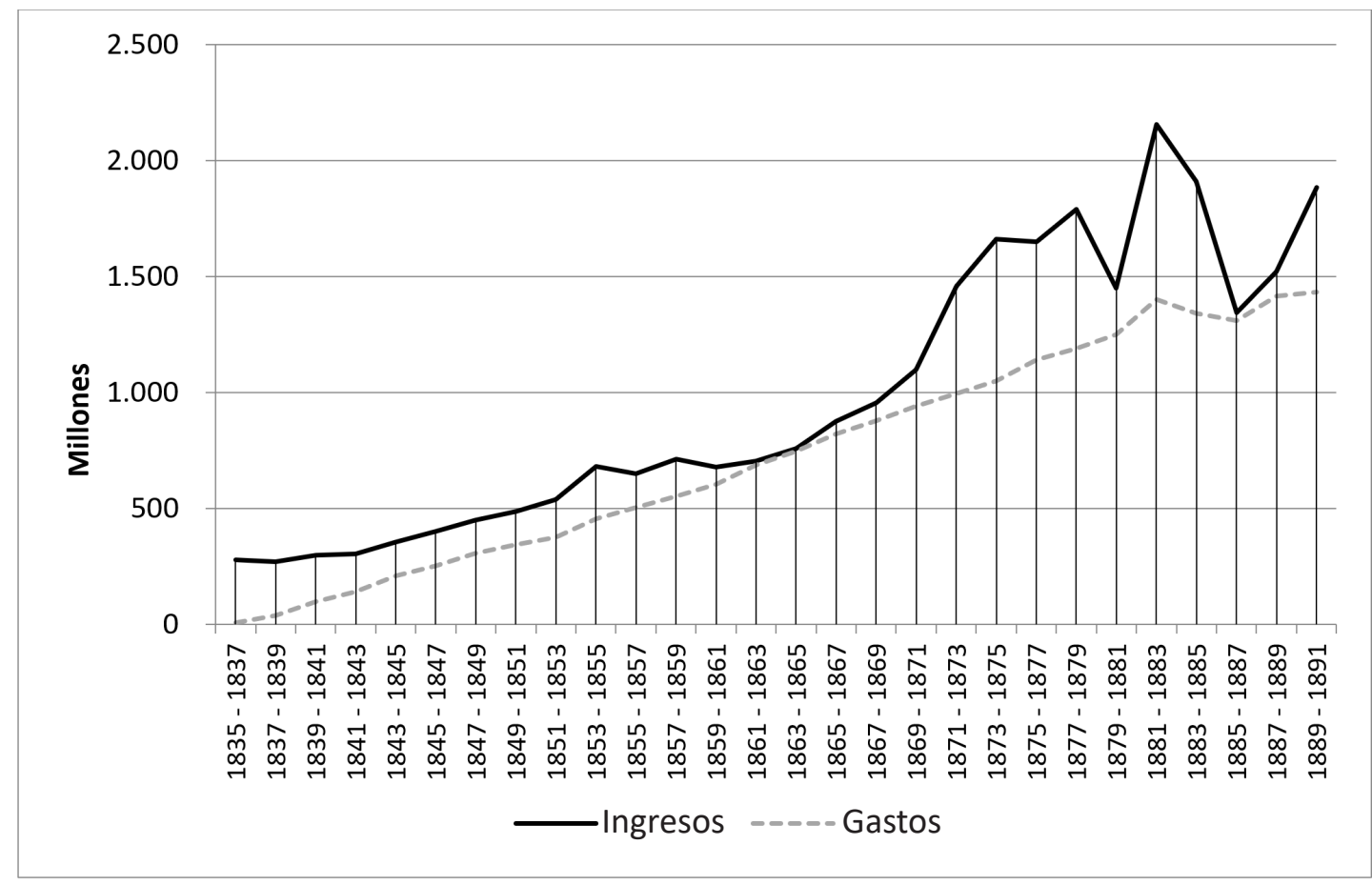

Fuente: Movimiento financiero del Montepio General de Economía de los Servidores del Estado - 1835/1883, en: PEREIRA, 1952. Anexo. 
a los gastos, principalmente con el pago de las mismas pensiones. La Tabla 1 demuestra los movimientos financieros del Montepio General de Economía de los Servidores del Estado con ingresos, gastos y saldos. A partir de ella construimos los gráficos siguientes que nos auxilian en el intento de entender la salud financiera de esa institución.

En los Gráficos 2, 3 y 4 podemos constatar que los pagos de las joyas, inscripciones y anualidades (ingresos) tenían valores muy por debajo de los gastos. Las cuentas sólo cerraban con los intereses pagados por las pólizas y por las rentas considerables dadas por las loterías (saldos). Estos dos activos, pólizas y loterías, sostenían el montepio incluso con algún descanso en algunos períodos.

Dentro de las fuentes de ingresos del Montepio a lo largo del período estudiado (1835/1883), la parte más pequeña fue aquella vinculada a los pagos efectuados por los socios, cerca del $24 \%$ de los valores totales. Las loterías concedidas por el gobierno y los intereses de las pólizas correspondían respectivamente al $35 \%$ y al $41 \%$ de la renta, conforme queda claro en el Gráfico 3. Esa situación demostraba la fragilidad del Montepio y el alto grado de dependencia hacia el Gobierno, lo que justifica tantas las injerencias políticas por parte de los presidentes y de la dirección de la institución. Diez años después de la fundación del Montepio de Economía de los Servidores del Estado, las mensualidades y las joyas no eran más suficientes para el pago de las pensiones de los socios - lo que nos muestra la falta de una planificación más racional o los 'abusos' por parte concesión de los beneficios. Estos ingresos variaron a lo largo del tiempo, sin embargo, desde su origen el Montepio de Economía de los Servidores del Estado fue dependiente de los ingresos de las pólizas y loterías, conforme se verifica en el Gráfico 3.

Podemos observar que, cuando la concesión de doce loterías para Montepio en vez de las cuatro anteriores en 1864, según lo visto, crecerá sustancialmente la participación de esa fuente de ingresos para la institución. En el bienio 1867 - 1869 las loterías sobrepasan el pago de las mensualidades y joyas como forma de recaudación, siendo que en el bienio de 1883 - 1885 hubo una caída significativa en esta renta y eso justificó el pedido de intervención del gobierno en las loterías provinciales. A partir del final de la década de 1870 podemos percibir que la renta dada por los pagos de los socios será declinante hasta el período final por nosotros analizado. También queda patente cómo los intereses generados por los títulos de la deuda pública fueron importantes y las más constantes fuentes de ingresos. Las pólizas de la deuda pública tuvieron también un crecimiento espectacular durante todo el período del montepio, pasando de 297:600\$000 (doscientos noventa y siete cuentos de rejas) en el bienio 1835 - 1837 a 7:554:700\$000 (siete mil, quinientos y cincuenta y cuatro cuentos y setecien-

Gráfico 3: Ingresos del Montepio General de Economía de los Servidores del Estado 1835/1891 (en réis)

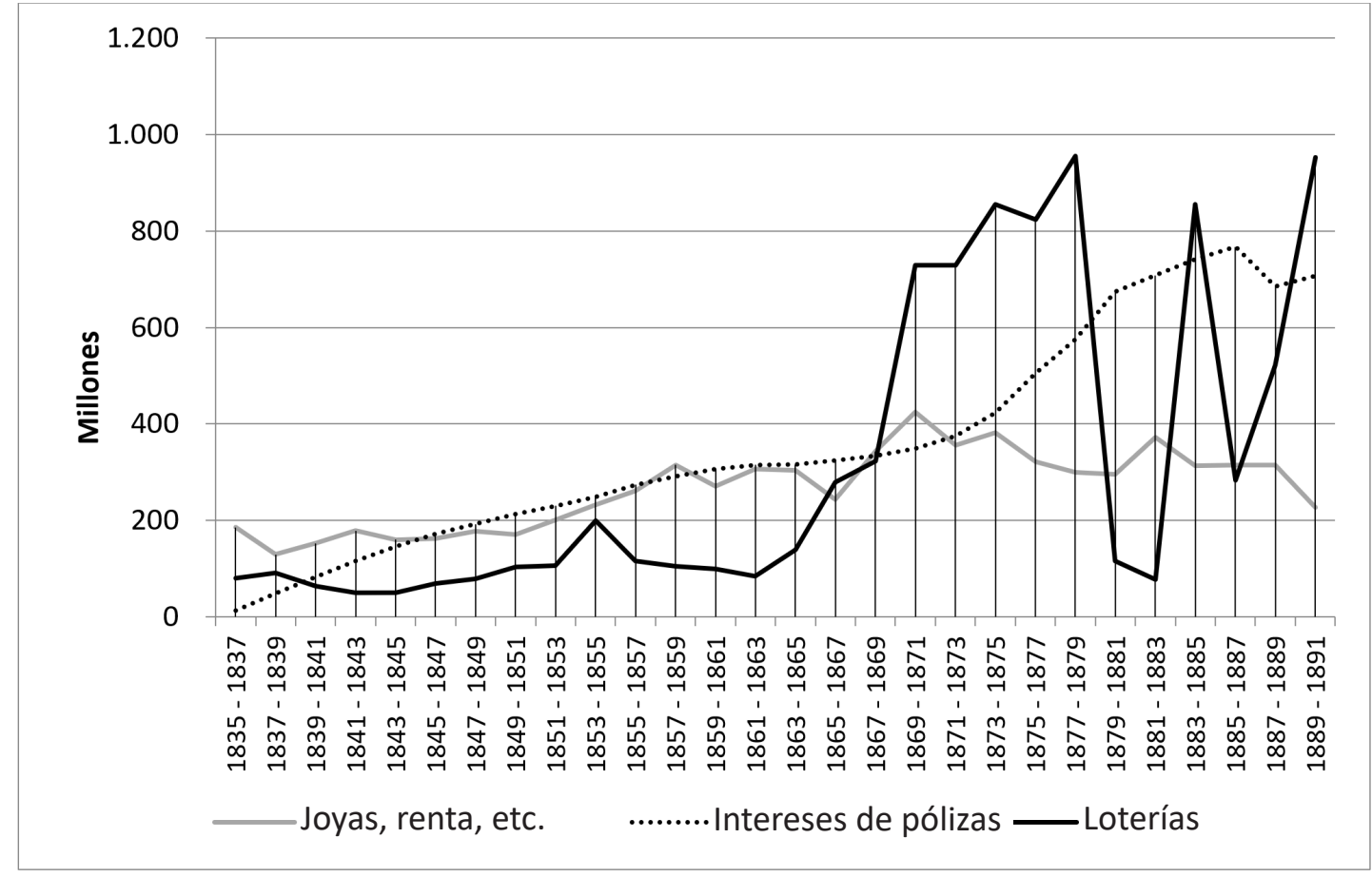

Fuente: Movimiento financiero del Montepio General de Economía de los Servidores del Estado - 1835/1883, en: PEREIRA, 1952. Anexo. 
tos mil reyes) o un crecimiento del orden de $2.538,54 \%$ para un período de 65 años. Este patrimonio era superior al de varios bancos existentes en el período, así, se percibe que, cuando el gobierno imperial reducía los intereses pagados por los títulos, la depreciación del patrimonio y rendimiento del montepio era considerable, provocando quejas constantes del directorio, como fue el caso si en 1885 cuando el gobierno pasó a pagar el $5 \%$ y no más el $6 \%$ de interés de las pólizas de la deuda pública.

La disminución del número de socios que se percibe en los informes de los años finales del Imperio agravarará la crisis de la institución lo que llevará a más reformas como las que en 1884 eliminaron "el goce de la pensión en vida" por los asociados y reglas más rígidas para la concesión de pensión a los parientes. Implicará también más socorros públicos como el perdón de deudas de préstamos contraídos al gobierno o el parcelamiento de los mismos. De este análisis sumario del Monte de los Servidores del Estado, vemos que el concepto de 'privado' era bastante relativo en una sociedad como la del Brasil Imperio. Sus finanzas demuestran además que la capacidad de este montepio de desdoblar sus inversiones en otros sectores de la economía fue bastante reducida, por no decir inexistente.

\section{Consideraciones finales}

La mayoría de los estudiosos asocia como uno de los factores del atraso de la economía y de la sociedad brasileña la inexistencia de un espíritu de cooperación entre los individuos de esa sociedad. En parte, fruto de la herencia ibérica que paradójicamente valoraba al individuo y, además, herencia de la esclavitud que, al rebajar el trabajo manual a las actividades desempeñadas por esclavos, reducía la importancia del trabajo en general.

Las experiencias de asociativismo en Brasil, por otro lado, tienden a ser estudiadas con énfasis en la segunda mitad del siglo XIX, y en las primeras décadas del siglo XX. Parte de ese énfasis está vinculada a la propia legislación que obligó a todas las asociaciones de ese tipo a someter sus estatutos a la aprobación del Estado imperial brasileño, a partir de 1860.

Lo que el estudio del Montepio de Economía General de los Servidores del Estado nos muestra es que más que una herencia del sistema colonial ibérico, las dificultades de las asociaciones mutuas en el país estaban ligadas también a la construcción del Estado brasileño en el siglo XIX que, al privilegiar las categorías sociales que construían la propia burocracia, dificultaban el desarrollo de otras categorías, cuando no lo inviabilizaban completamente, como en el caso de las Cajas Económicas.

Gráfico 4: Gastos del Montepio General de Economía de los Servidores del Estado 1835/1891 (en réis)

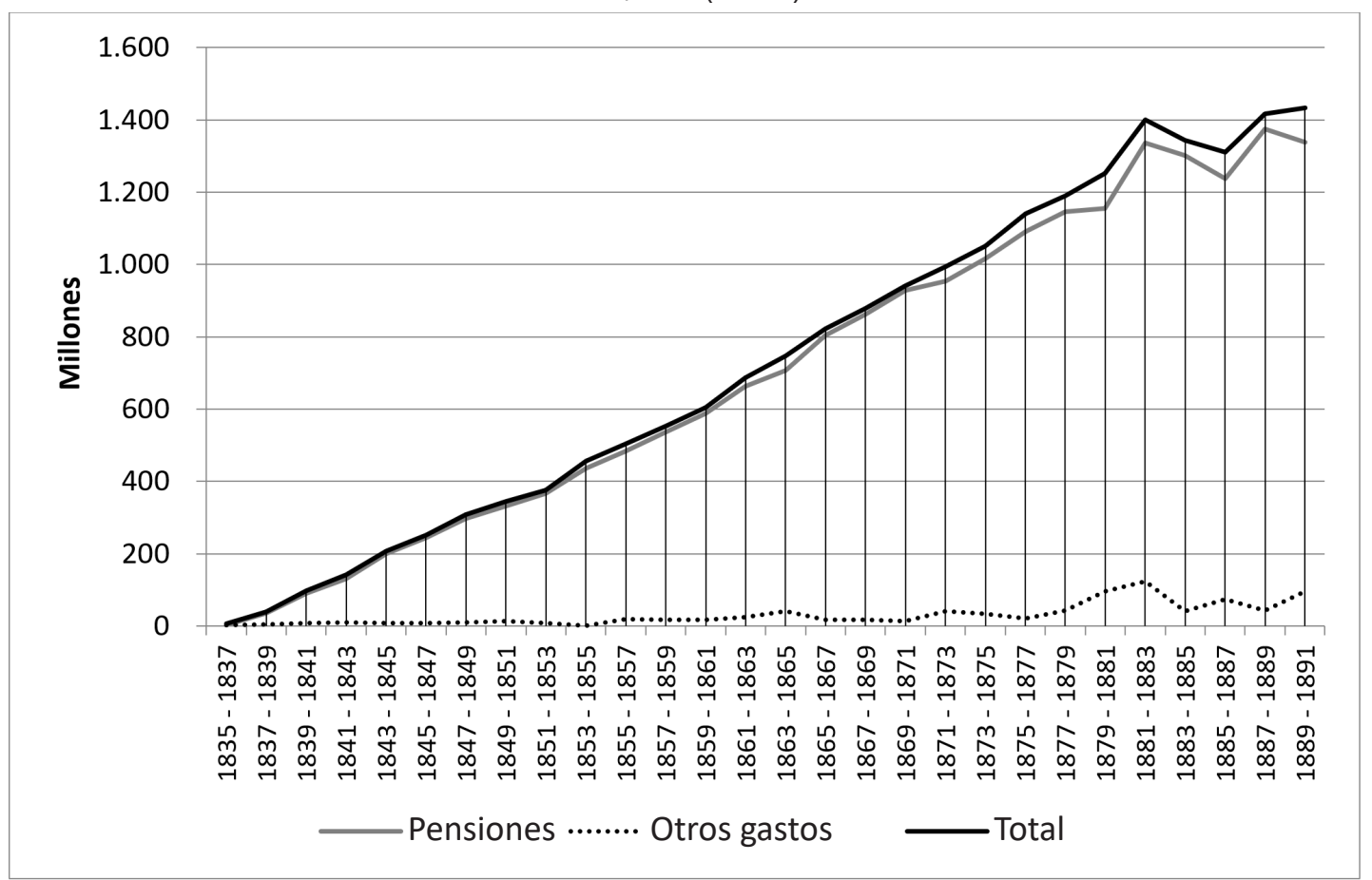

Fuente: Movimiento financiero del Montepio General de Economía de los Servidores del Estado - 1835/1883, en: PEREIRA, 1952. Anexo. 
Bibliografía

ALMICO, Rita C. S.; SARAIVA, Luiz F. (2008): "Casa Montepio dos Artistas: Pecúlio e auxílio mútuo em uma sociedade do Recôncavo da Bahia". Congreso Internacional de Historia de las Cajas de Ahorro. Universidad de Murcia.

ALMICO, Rita de Cássia da Silva (2015): Em nome da palavra e da lei, Rio de Janeiro, Editora 7 Letras.

BARICKMAN, Bert Jude (2003): Um contraponto baiano: açúcar, fumo, mandioca e escravidão no Recôncavo. 1780-1860, Tradução de Maria Luiza X. de A. Borges, Rio de Janeiro, Civilização Brasileira.

CABARRÚS, Francisco (1783): Cartas sobre los obstáculos que la naturaleza, la opinión oponen a la felicidad pública, Barcelona, Imprenta de D.A. Roca.

CARDOSO DE MELLO, João Manuel (1985): O capitalismo Tardio, São Paulo, Brasiliense.

CARVALHO, José Murilo de (1980): A construção da ordem: a elite política imperial, Rio de Janeiro, Ed. Campus Ltda.

CHRISTEN-LÉCUYER, Carole (2004): Histoire Sociale er Culturalle des Caisses D'Epargne em France (1818-1881), Paris, Editora Economica.

FERREIRA, Luiz Otávio, (1998): "José Francisco Xavier Sigaud: um personagem esquecido, uma obra reveladora", História, Ciência, Saúde/Manguinhos, 5 (1), pp. 125-126.

FRANCO, Maria Sylvia de Carvalho (1969): Homens Livres na Ordem Escravocrata, São Paulo, Editora da UNESP.

FRANCO, Renato Júnior (2014): "O modelo luso de assistência e a dinâmica das Santas Casas de Misericórdia na América portuguesa". Estudos Históricos, 27, pp. 5-25.

FREYRE, Gilberto (1983): Casa Grande \& Senzala, 22a edição, São Paulo, Rio de Janeiro, Livraria José Olympio.

GUIMARÃES, Carlos Gabriel (1997): Bancos, Economia e Poder no Segundo Reinado: O Caso da Sociedade Bancária Mauá, Macgregor \& Companhia (1854-1866), Tese de Doutoramento, São Paulo, Universidade de São Paulo.

HOLLANDA, Sérgio Buarque de (1995): Raízes do Brasil, São Paulo, Cia. Das Letras.

LEMONTEY, Pierre-Arnold, publicado por José Francisco Sigaud (1832): O Homem Benfazejo ou das Vantagens que Resultam da Fundação da Caixa Econômica dos Povos Civilizados, Rio de Janeiro, Tipografia Imperial Constitucional de Seignot-Plancher \& Cia, vol. XII, Biblioteca Constitucional do Cidadão Brasileiro.

LEVY, Maria Bárbara (1994): A Indústria do Rio de Janeiro através de suas sociedades anônimas, Rio de Janeiro, Biblioteca Carioca/UFRJ.

MALERBA, Jurandir (2003): Esboço crítico da recente historiografia sobre a independência do Brasil (desde C. 1980), University of Oxford, Centre for Brazilian studies, working paper number, CBS-45-03.

MARTÍNEZ SOTO, Ángel Pascual (2018): La protección social en la época liberal: de la beneficencia a la previsión social (1820-1908), Murcia, Areas. Revista Internacional de Ciencias Sociales, 37, pp. 109-126.

MARTÍNEZ SOTO, Ángel Pascual, CUEVAS CASAÑA, Joaquim y HOYO APARICIO, Andrés (2005): "La Historia Económica de las Cajas de Ahorros Españolas: Una perspectiva institucional y regional del ahorro, 18302004", Papeles de Economía Española, 105/106, pp. 6-15.

MARTINS, José de Souza (1979): O cativeiro da terra, São Paulo, Símbolo.

MATOSO, Kátia de Queiroz (1992): Bahia Século XIX, uma província no Império, 2a edição, Rio de Janeiro, Editora Nova Fronteira.

MATTOS, Ilmar Rohloff de (2004): O Tempo Saquarema. $5^{\text {a }}$ edição, São Paulo, Editora Hucitec.

MOTA, Carlos Guilherme (1986): 1822: Dimensões, São Paulo, Perspectiva.

NEVES, José Acursio das (1814): Variedades sobre objetos relativos as artes, comércio e manufaturas, consideradas segundo os princípios da Economia Política. Lisboa, Impressão Régia.

NOVAIS, Fernando Antônio (1995): Portugal e Brasil na crise do antigo sistema colonial (1777-1808), 6a edição, São Paulo, Ed. Hucitec.

OLIVEIRA, Geraldo Beauclair Mendes de (1992): Raízes da indústria no Brasil: a pré-indústria fluminense, 1808-1860, Rio de Janeiro, Studio F\&S.
PEREIRA, Alfredo Leal de Sá (1952): Montepio Geral de Economia dos Servidores do Estado - Ligeiro Resumo do seu 10 Centenário 1835/1935, Rio de Janeiro, (reeditado), Jornal do Comércio.

PEREIRA, Ronaldo (2002): Associações de classe, profissionais e beneficentes do Rio de Janeiro (1860-1889), São Paulo, USP, Caderno de debates.

PEREIRA, Vantuil (2010): Ao soberano congresso: direitos do cidadão na formação do estado imperial (1822-1831), São Paulo, Casa Alameda Editorial

PIÑEIRO, Théo Lobarinhas (2002): Os "simples comissários": negociantes e política no Brasil Império (1831-1888), Tese de Doutorado, Niterói, UFF/PPGH.

PIRENNE, Henri (1963): História Econômica da Idade Média, Tradução de Lycurgo Gomes da Motta, São Paulo, Mestre Jou.

PISTOLA, Renato José Bogalho Jorge da et al. (2018): Entre mutualismo e capitalismo: os caminhos do Montepio Geral (1840-1930).

PRADO JÚNIOR, Cai (2000): Formação do Brasil Contemporâneo, São Paulo, Brasiliense/ Publifolha.

REIS, João José (1991): A Morte é uma Festa: ritos fúnebres e revolta popular no Brasil do século XIX, São Paulo, Cia. das Letras.

SARAIVA, Luiz. Fernando; FRANÇA, Lílian S. (2011): “Os Atos do Poder Legislativo no Império Brasileiro (1826-1889)", Revista Internacional de História Política e Cultura Jurídica, 3, pp. 5-32.

SCHWARTZ, Stuart (2001): Escravos, Roceiros e Rebeldes, Tradução de Jussara Simões, Bauru, São Paulo, Ed. da Universidade Sagrado Coração.

SILVA JÚNIOR, Adhemar Lourenço da (1999): “Estado e mutualismo no Rio Grande do Sul (1854-1940)", Estudos Ibero Americanos, XXV, (2), pp. 147-174.

SILVA, Maria Conceição Barbosa da Costa e, (1998): O Montepio dos Artistas Elo dos Trabalhadores em Salvador, Salvador, Secretaria da Cultura e Turismo do Estado da Bahia, Fundação Cultural, EGBA.

SOUZA, Ana Maria dos Santos Pereira de (2003): Comprometimento or ganizacional em contexto de fusões \& aquisições: Estudo de caso em trajetória de organização bancária, Salvador, Universidade Federal da Bahia, mestrado profissional em Administração.

VATIN, François (2006): "Pierre-Édouard Lemontey, L'invention de la sociologie du travail et la question salariale", Revue du Mauss, 27, pp. 398-420. 